\title{
A DYNAMIC INPUT-OUTPUT MODEL FOR SMALL REGIONS
}

\author{
Thomas G. Johnson*
}

\section{Introduction}

Since the early experimentations with inputoutput analysis (Leontief, 1936, 1941), numerous variations have been offered. Few variations have attracted more attention than those that attempt to generalize the static model over time. These variations have ranged from the very simple to the highly sophisticated; from the very successful to the less than satisfactory; and from the conceptually sound to something less.

Another issue is related to the appropriateness of input-output analysis to small versus large economies. Input-output has been applied to international economies on one extreme and to cities and communities on the other. Are there conceptual or empirical arguments which favor the application of this tool to economies of a particular size?

This paper develops a conceptual foundation for temporal input-output, reviews the experiences in the area and looks at its potential, particularly for small region modeling. Finally, a particular dynamic input-output model is described and examined in light of this conceptual foundation.

\section{Intertemporal Input-Output Models}

Economists have long been interested in the temporal dimension of almost all economic activities. Input-output analysts have been no exception. Wassily Leontief introduced his dynamic version of input-output with the statement,

"A static theory derives the changes in the variables of a given system from the observed changes in the underlying structural relationships: dynamic theory goes further and shows how certain changes in the variables can be explained on the basis of fixed, i.e. invariant, structural characteristics of the

*Associate Professor, Department of Agricultural Economics, Virginia Polytechnic Institute and State University. system.

"Dynamic theory thus enables us to derive the empirical law of change of a particular economy from information obtained through the observation of its structural characteristics at one single point of time" (1953, p. 53).

Moore and Petersen $(1955$, p. 368$)$ state that a dynamic element is needed in input-output models "if the model is to be used for the analysis of regional business cycles, industrial growth and technological change, or for the computation of period (that is, truncated) multipliers."

There are three major features which distinguish static from dynamic input-output models. First, as Leontief points out, the static model makes predictions given observed structural changes (such as increased or decreased investment) while a dynamic model would explain these structural changes on the basis of more fundamental, invariant structural features (such as investment functions). A static model does not, therefore, predict changes in "stock like" variables whereas a dynamic model does. Second, the solution to the static model is timeless. The impact of final demand requirements, while requiring multiple time periods to work through the entire system, are telescoped by the inverse matrix to show a single, total adjustment in each sector (Moore and Petersen, 1955, p. 380). Thus, the static model integrates, over time, and condenses the time path of reactions into its timeless sum (Moore, 1955).

Third, the static model is an equilibrium device. Its solution indicates a set of circumstances in which there are no net forces of change acting upon the variables. This static equilibrium has a corresponding dynamic counterpart. One can imagine that at any point in time, there is a set of circumstances in which there would be no net forces of change acting on the variables. One can also imagine a model which describes the changes in these circumstances above, what we might call a "dynamic equilibrium" model. These models, known as turnpike models, have been studied 
in some detail (Tsukui and Murakami, 1979). As Sargan $(1958$, p. 381) points out, such a model is incompletely dynamic since it does not describe the economy's "movement" with respect to this equilibrium. A dynamic disequilibrium model, on the other hand, would describe the economy's reaction path as it moves in response to the net forces for change. Depending on these forces, the economy may move toward or away from the equilibriumquickly or slowly; smoothly or on an irregular path; or in any other fashion dictated by the relationships governing the dynamics of the system. The equilibrium conditions are a timeless, instantaneous function of the actual circumstances at a point in time whereas the disequilibrium relationships involve lags, rates of change, and other temporal functions.

Together those features of the static model-its partiality, its timelessness and its equilibrium nature-distinguish it from the ideal dynamic input-output model. As Leontief has pointed out, progress toward this ideal can only be partial since the list of hypothetically relevant determinants of structural change include many which "will remain beyond the reach of the empirical investigator for a long time to come" (1953, pp. 53-54).

\section{Input-Output in Small Region Analysis}

Bourque, Conway, and Howard (1977, p. 4), in describing the Washington State Projection Model, one of the better known temporal inputoutput models, list three appealing features of input-output: "An explicit, logical, yet flexible structure; a detailed and comprehensive coverage of economic variables; and internally consistent projections." The input-output model imposes a theoretical, causal framework on the analyst. It is precisely this imposition which provides the strength of the input-output approach. Unlike econometric models, which are usually composed of reduced form equations chosen on the basis of statistical criteria, input-output is based on structural equations. Reduced form equations predict well as long as certain trends and indirect or coincidental relationships continue. In any other case the structural equation approach is preferable.

But the features above are equally important in national, regional and community level analyses and apply equally to static and dynamic models. Does input-output-particularly dynamic input-output-offer any special advantages to regional as opposed to national analysts? Let us explore the dynamic model first, before we consider its appropriateness to small regions.

\section{Experiences With Dynamic Input-Output}

The most obvious way of adding a temporal dimension to input-output is to calculate periodic solutions to the static model (Tung, MacMillan and Framingham, 1976; Emerson, Lamphear and Atencio, 1969; Rubida, 1978; Bourque, Conway, and Howard, 1977; Treyz and Ehrlich, 1982; Almon, et al, 1974; Bodkin, 1976; Fromm and Klein, 1975; and Preston, 1976). In each of these applications the telescoped solution to the static model, which conceptually requires an infinite number of rounds to achieve, is attributed to whatever length of time the econometric model is estimated for-years, quarters or even months. Some models of this type incorporate capacity constraints and other temporal features, yet these models fall far short of fully dynamic models.

Some variations on this general theme have been proposed. Moore and Petersen (1955) discuss the possibility of letting the terms of the power series solution to the static model $\left.\mathrm{I}+\mathrm{A}+\mathrm{A}^{2}+\mathrm{A}^{3}+\ldots\right)$, each represent a round of transactions. They then assume that a fixed number of transactional rounds, say three, will occur each year. Johnson (1980) assumes that 80 percent of the total impact would occur in the first year, 15 percent in the second, and 5 percent in the third year. Neither of these approaches is very satisfactory because of their lack of sectoral specificity, empirical bases and conceptual foundation.

Leontief introduced a dynamic equilibrium input-output model in 1953 with his paper on dynamic analysis (pp. 53-90). This original model introduces the concept of time paths of stimulae (final demand) and consequences (sectoral output) and thus has an explicit temporal dimension. Leontief's model endogenizes investment levels and thus makes some progress towards his ideal of deriving "the empirical laws of change of a particular economy" (1953, p. 53). However, the model assumes that the economy is continuously in equilibrium and does not, therefore, reflect the actual "reaction path" of variables. 
Leontief's dynamic model follows directly from the static model once one reinterprets (or more precisely interprets) the technical coefficients. If one views each $a_{i j}$ in the $A$ matrix as an average rate of flow of inputs from sector $i$ to sector $j$ (or money from sector $j$ to sector $i$ ) over one unit of time, then the final demand, $Y$, and sectoral output, $\mathrm{X}$, acquire temporal dimensions. The static balance equation is transformed into

(1) $x(t)=A x(t)+y(t)$.

Leontief separated final demand into the rate of change in capital stocks, $\dot{s}(t)$, and other final demands, $y(t)$. This transforms the equation into (2) $x(t)=A x(t)+y(t)+\dot{s}(t)$,

where $\dot{s}(t)$ is the time derivative of $s(t)$. If it is assumed, as Leontief does, that capital stocks are linear, homogenous functions of industry output then,

(3) $s(t)=B x(t)$, and

(4) $\dot{s}(t)=B \dot{x}(t)$,

where $B$ is an nxn matrix of capital-output coefficients. Substituting gives the first order differential equation,

(5) $x(t)=A x(t)+y(t)+B \dot{x}(t)$

which has the solution,

(6) $\mathrm{x}(\mathrm{t})=\hat{\mathrm{c} K} \exp (\mathrm{t} \lambda)+1(\mathrm{t})$,

where $K$ is an nxn matrix and $\lambda$ an $n x l$ vector of constants depending on the coefficients in $\mathrm{A}$ and $\mathrm{B} ; \hat{\mathrm{c}}$ is an $\mathrm{nxn}$ diagonal matrix of constants reflecting the initial conditions (i. e., the constants of integration); $1(\mathrm{t})$ is an $\mathrm{nxl}$ vector of relationships for the $n$ sectors, $y(t)$. This solution is developed in detail by Leontief (1953, pp. 76-82). Equation (6) is a system of n equations. If $1(t)$ and the initial conditions are specified, then the time form of the $n$ outputs $\mathbf{x}(\mathrm{t})$ can be predicted. Alternatively, if both the initial conditions and the terminal conditions are specified, then as many as n parameters of the $1(t)$ functions can be calculated. This allows the estimation of required final demand time paths to achieve any specified output objectives.

Leontief has also introduced a discrete approximation of equation (5) where the derivative $x(t)$ is replaced by $\left(x_{t+1}-x_{t}\right)$ giving the difference equation,

(7) $x_{t}=A x_{t}+y_{t}+B\left(x_{t+1}-x_{t}\right)$.

Several means of solving these difference equations have been proposed. The simplest approach is to set the terminal conditions to assumed levels, such that

(8) $x_{t}=A x_{t}+y_{t}-B x_{t}$, and then to substitute this value of $x_{t}$ into the equation for the previous period,

(9) $x_{t-1}=A x_{t-1}+y_{t-1}+B\left(x_{t}-x_{t-1}\right)$, and solve. This backward, recursive procedure is repeated until the desired initial period is reached. This procedure is detailed in Miernyk, et al. (1970), and Liew (1977). A more formal representation of this procedure is offered by the dynamic inverse (Leontief, 1970). Variants of this procedure are suggested by Almon (1966); Kendrick (1972); Liew (1977); and Schinnar (1978). An interesting feature of this discrete solution is that all previous time periods depend on the terminal conditions. It implicitly assumes that producers and investors have perfect foresight and produce the exact level of output needed to satisfy all future investment and exogenous final demand.

The assumption of equilibrium conditions in a model that allegedly traces a dynamic reaction leads to unacceptable projections. First, it assumes that investment is instantaneous and completely reversible. These assumptions allow unrealistically rapid accumulations and decumulations of capital as Leontief's empirical experiments demonstrate $(1970$, p. 23). A related assumption, that there are neither capacity constraints nor excess capacities, is also very unrealistic. In addition, it assumes that there are no lags in the interindustry relations-that production (as well as investment) changes instantaneously with changes in demand.

The endogenization of investment does not change the fact that the balance equation still describes a long-run equilibrium. The model is void of any relationships describing change in the system other than its requirement that the economy be in equilibrium at all times. Unfortunately, in requiring the system to be in equilibrium, changes are required of it which often move the equilibrium off in a divergent direction, at an accelerating rate. Simply stated, the original Leontief dynamic model describes the conditions under which the economy will be in equilibrium, but it does not adequately indicate how it will get there.

Leontief recognized the need to relax these assumptions and suggested general ways of doing so. This paper describes a model which incorporates some of Leontief's suggestions, as well as other features which make it a disequilibrium model. This disequilibrium feature 
is achieved by amending the balance equations to allow for short term imbalances between the rates of production and demand.

Consider the revised form of balance equation (1),

(10) $x(t)=A x(t)+y(t)+i(t)+e(t)$, where $e$ is an $n \times 1$ vector of instantaneous rates of excess production over use of each commodity. The vextor $i(t)$ is the rate of gross investment and replaces $\dot{s}(t)$ in order that depreciation may be recognized. Rearranging,

(11) $e(t)=x(t)-A x(t)-y(t)-i(t)$.

This framework allows $x(t)$ to equal something other than the sum of $A x(t), y(t)$ and $i(t)$ as it does at equilibrium. This excess (positive or negative) of production over use or consumption represents an instantaneous rate of addition to the economy's stocks of the product, and in that sense is related to the rate of change in inventories. To call them the rate of change in inventories is not correct, however, because real inventories are usually included in capital stocks, s(t), making their level a positive function of output at equilibrium. The value of $e(t)$, since it is zero at equilibrium, influences inventories' only as the system moves toward equilibrium. Inventories will, therefore, fluctuate both above and below the equilibrium level depending on whether current production is greater than or less than current rates of use.

The next step is to specify a dynamic disequilibrium relationship. For the static and dynamic balance equations to represent an equilibrium, our relationship must specify that $\dot{x}(t)=0$ when $e(t)=0$. Furthermore, for the equilibrium to be stable, $\partial \dot{x}(t) / \partial e(t)<0$.

Following Sargan (1958), it is hypothesized that the rate of change in the rate of production is a linear function of $e(t)$, that is,

(12) $\dot{x}(t)=\stackrel{\phi}{e}(t)$, or

(13) $\dot{x}(t)=\hat{\Phi}[A \quad x(t)+i(t)+y(t)-x(t)]$,

where $\hat{\Phi}<0$ is a diagonal matrix of each sector's acceleration constant, since it indicates the speed with which a sector changes its rate of production in response to changes in the rate of demand. This equation introduces a simple Lundbergian type exponential lag as proposed by Allen (1967, pp. 163-169).

For those sectors which are constrained by a capacity rate of production, we add the constraint,

(14) $x(t) \leq x^{c}(t)$.
The next step is to develop an investment function which depends on current production and sector capacity, but which involves a lag and is limited to realistic levels. We hypothesize the following function:

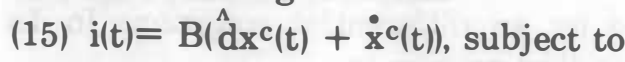

(16) $\mathrm{i}(\mathrm{t}) \geq 0$.

This is equivalent to the condition

(17) $\dot{x}^{c}(t) \geq-\hat{d} x(t)$,

which requires gross investment to be greater than or equal to zero. The diagonal matrix $\hat{d}$ contains periodic capacity depreciation rates. Equation (15) thus distinguishes replacement investment, $B \hat{d} x^{c}(t)$, from net (induced) investment, $B \dot{X}^{c}(t)$. This concept is identical to that of fixed capital extensions in Green (1975); Gossling (1975); and McLewin (1975). This approach was suggested by Leontief $(1953$, pp. 68 72 ), but he was unable to satisfactorily incorporate it into his analytic model since it introduced discontinuities. Leontief proposed a phase theory to introduce these discontinuities. This concept has been adopted in this model and extended to include other discontinuities.

Next, a behavioral relationship which predicts the actual capacity vector, $x^{c}(t)$, is required. It is hypothesized that the desired level of capacity at any point in time is a linear function of the rate of production at the time; that is,



where $\mathbf{x}^{c^{*}}(t)$ is the desired capacity, $\alpha$ is an $n \times 1$ vector of intercepts (representing a desirable, constant buffer of excess capacity), and $\beta$ is a diagonal matrix of slopes (representing the desirable ratio of capacity to demand). This rather simplistic relationship could be made more complicated by adding a term for the rate of change in production, $\dot{x}(t)$, if desired. Actual capacity is in turn some delayed or lagged function of desired capacity. This lag may be discrete as in

(19) $x^{c}(t)=x^{c^{*}}(t-\tau)$

where $\tau$ is a constant structural lag, but is more likely to be some continuous lag such as the exponential lag; that is,

(20) $\dot{x}^{c}(t)=k\left[x^{c^{*}}(t)-x^{c}(t)\right]$

where $\hat{k}$ is a diagonal matrix of constants which determines the length of lag for each sec- 
tor. This lag structure has been suggested and interpreted by Allen (1967) and by Bargur (1969).

This completes the model. By making appropriate substitutions this model can be described by $4 n$ differential equations in $4 n$ unknowns. The system is:

$$
\begin{aligned}
& \text { (21a) } \dot{x}(t)=\hat{\Phi}[A x(t)+y(t)+i(t)-x(t)], \\
& \text { (21b) } i(t)=B\left[\hat{d} x^{c}(t)+\dot{x} c(t)\right], \\
& \text { (21c) } \dot{x} c(t)=k\left[x^{c^{*}}(t)-x^{c}(t)\right], \\
& \text { (21d) } \left.\left.\dot{x} c^{*}(t)=\alpha+\hat{\beta}[A x) t\right)+y(t)+i(t)\right]
\end{aligned}
$$

subject to the $2 \mathrm{n}$ constraints

(22a) $x(t) \leq x^{c}(t)$,

(22b) $\dot{x}^{c}(t) \geq-\hat{d} x^{c}(t)$.

These six types of equations and inequalities may be solved analytically but only with great effort. A new solution is required each time any sector meets a constraint (i.e. at each phase change). An alternative is to numerically integrate the differential equations and to simulate the system through time, checking continuously for phase changes. The algorithm (see Johnson, 1983) exhibits stability, makes feasible projections, allows the analyst to simulate from any set of initial conditions, and perhaps most importantly, tracks history reasonably well.

The model has been fitted with data from the Grant County Input-Output Model and used to analyze the dynamic impacts in the county. The Grant County Model is a primary survey model based on 1977 transactions. It includes 19 industries plus households, local governments, state and federal governments, capital costs, and imports.

One of the scenarios chosen is related to a major expansion in one of the county's larger industries-wood products. An increase in allowable timber cut worth $\$ 12,647,000$ is assumed to materialize over a one year period. The county's economy is monitored for six months prior to the change, during the change, and for the following three and one half years. The levels of certain key variables are plotted for this period in Figures 1 and 2. Figure 1 plots the levels of output, demand, capacity and investment in the wood products industry. Figure 2 shows the trajectories of aggregate income, investment and taxes, and the output of several industries other than wood products.



FIGURE 1: OUTPUT, CAPACITY, FINAL DEMAND AND INVESTMENT IN WOOD PRODUCTS INDUSTRY 
In Figure 1 the wood products industry is essentially in equilibrium for the first six months ( $t \quad 0$ to $t=.5$ ). Capacity is at about the desired level given the level of output. Final demand for wood products (about $\$ 36.5$ million) leads, through the multiplier effect, to an output of about $\$ 38.5$ million. At $t=.5$, the final demand begins to rise. Between $t=.5$ and $t=1.5$ it rises $\$ 12.5$ million to $\$ 49$ million. Output responds by rising until it bumps its capacity constraint at $\mathrm{t}=1.5$. Due to investment, capacity is rising but is subject to a longer lag than output. Between $t=.5$ and about $t=2.5$, output in the wood products industry is equal to capacity. From $t=2.5$ to the end of the simulation, capacity continues to rise towards its desired level, despite the decline in investment.

Figure 1 illustrates two time events-the start and the end of the increase in final demand (at $t=.5$ and $t=1.5$ respectively), and two phase changes-contact with, and easing of the capacity constraint (at about $t=1.5$ and $t=2.5$ respectively). Notice also that capacity lags investment which in turns lags the rise in final demand.

Figure 2 not only demonstrates the multi- plier effect of wood products on other sectors of the economy but also the timing of these effects. The multiplier has its earliest effect on the construction industry followed by trade and services. The most lasting effect is on the timber hauling industry.

Figures 1 and 2 demonstrate the power and comprehensiveness of this dynamic inputoutput model. Static input-output models predict equilibrium levels of output in each industry, local taxes, and income. If the analyst can independently estimate the equilibrium level of aggregate investment (which is exogenous to the static model but endogenous to the dynamic model), then the equilibrium levels predicted in the static and dynamic versions are identical.

This demonstrates the relationship between the static equilibrium and the dynamic disequilibrium models-that is, the latter traces the "reaction path" from one static equilibrium to another. Of course, any given static equilibrium can only be approached asymptotically.

Experimentation has demonstrated that for the Leontief assumption of instantaneous response, the model is unstable and unable to project a time path.

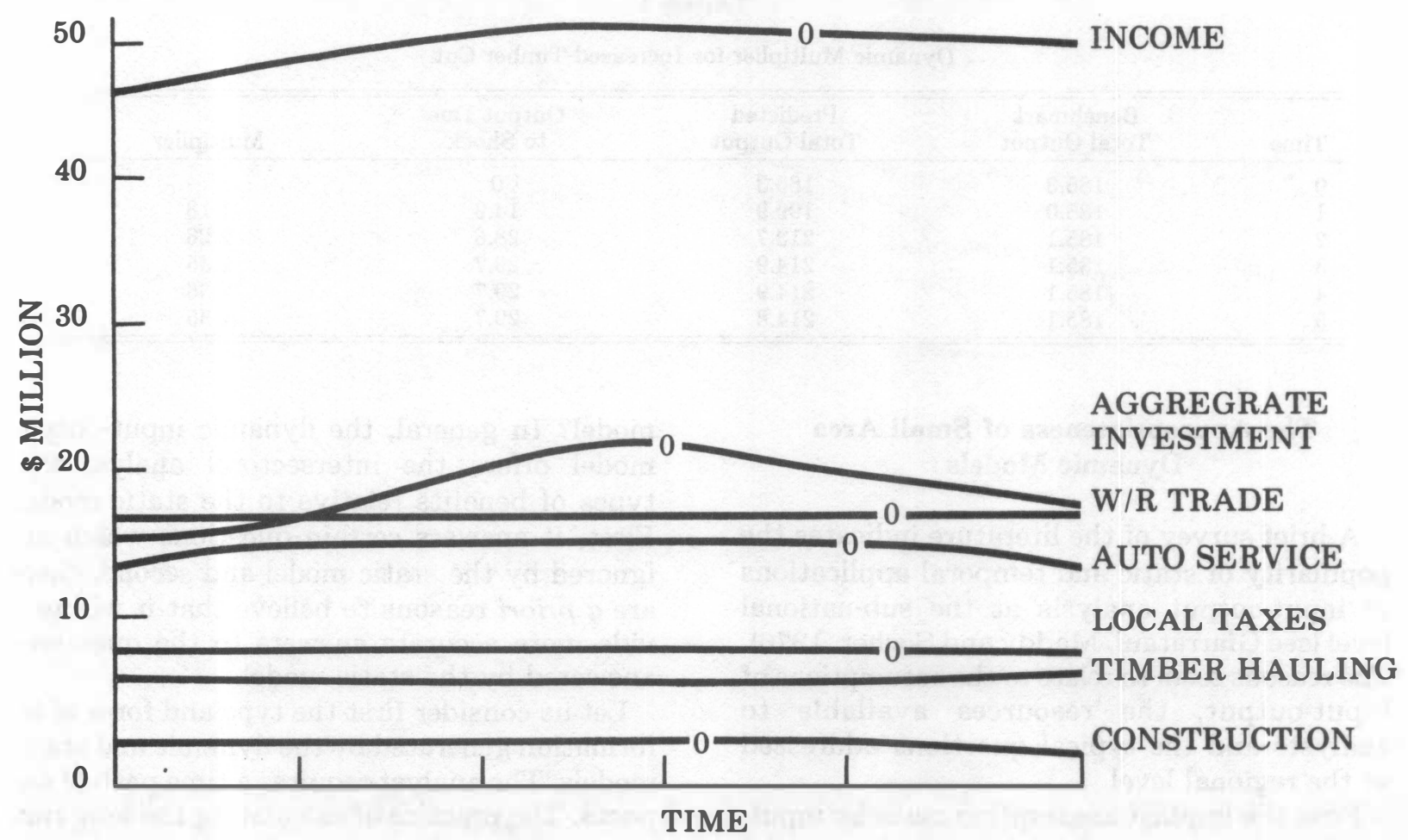

NOTE: 0 INDICATES LOCAL MAXIMUM

FIGURE 2: SELECTED VARIABLES 
It is possible, as in the static model, to calculate multipliers. Dynamic multipliers, however, reflect not only the magnitude of the impact but also the timing of it. The multiplier effects of the above shock are calculated on an annual basis in Table 1. These multipliers correspond to type II static multipliers since the model is closed with respect to the household sector. The static multiplier calculated is 2.26 , considerably lower than its dynamic counterpart. This is so because of the accelerator principle which recognizes that any lasting increase in output requires a larger capital stock which in turn requires higher levels of replacement investment.

The dynamic model provides the analyst with much more information. In addition to the equilibrium levels, it predicts the time paths from the initial levels to the final levels, it shows the lead and lag relationships between variables, it shows the effects of capacity constraints on output, and it predicts investment levels endogenously. For many purposes, the dynamic features of economic impact are essential pieces of information. ture, is most relevant in an open economy. In general, the smaller an economy, the more specialized its base and, therefore, the more open it is.

Other assumptions made by input-output also make it more appropriate for regional applications. Exogenous price and wage levels, and exogenous interest rates are assumptions which are least restrictive when marginal changes are being considered. Others such as unconstrained plant capacities and labor supplies are more serious but perhaps no more so than at the national level.

Finally, input-output models are well suited for answering the questions typically asked by regional analysts. What would be the effect of increased exports or government spending? What impact would the closure of a key firm have on the economy? How much total production is due to a given industry? How much will gross regional product change if a certain policy is undertaken? These and other questions are easily answered by input-output.

Can dynamic input-output contribute more to a regional analysis than can the static

TABLE 1

Dynamic Multiplier for Increased Timber Cut

\begin{tabular}{lcccc}
\hline \hline Time & $\begin{array}{c}\text { Benchmark } \\
\text { Total Output }\end{array}$ & $\begin{array}{c}\text { Predicted } \\
\text { Total Output }\end{array}$ & $\begin{array}{c}\text { Output Due } \\
\text { to Shock }\end{array}$ & Multiplier \\
\hline 0 & 185.3 & 185.3 & 0 & 1.18 \\
1 & 185.0 & 199.9 & 14.9 & 2.26 \\
2 & 185.1 & 213.7 & 28.6 & 2.35 \\
3 & 185.1 & 214.9 & 29.7 & 2.36 \\
4 & 185.1 & 214.9 & 29.7 & 2.35 \\
5 & 185.1 & 214.8 & 29.7 & \\
\hline \hline
\end{tabular}

\section{The Appropriateness of Small Area Dynamic Models}

A brief survey of the literature indicates the popularity of static and temporal applications of input-output analysis at the sub-national level (see Giarratani, Maddy and Socher, 1976). The reasons seem to relate to the assumptions of input-output, the resources available to analysts and the typical questions addressed at the regional level.

First the implicit assumption made by inputoutput, that economic activity is determined by the level of final demand, particularly households, exports and government expendi- model? In general, the dynamic input-output model offers the intersectoral analyst two types of benefits relative to the static model. First, it answers certain questions which are ignored by the static model and second, there are $a$ priori reasons to believe that it will provide more accurate answers to the questions answered by the static model.

Let us consider first the type and form of information generated by the dynamic and static models. The analyst requires a time path of impacts. The practice of calculating the long run, static impact of each periodic expenditure and attributing it totally to that period is clearly wrong. The seriousness of the problem depends 
on the actual length of time required to exhaust the total impact. Research with the dynamic input-output model (Johnson, 1979) suggests that certain indirect impacts take three or more years before they are substantially exhausted. Furthermore, it indicates that different sectors are impacted at different rates. These observations cast serious doubt on the advisability of using the static model in intertemporal frameworks. The dynamic model presented here essentially takes the long-run solution of the static model and plots its time path. This timing dimension is often as important as the total impact.

Another type of information projected by the dynamic model is the investment levels. By the standards of many macroeconomic models, the assumed relationships governing investment (equations (21b), (21c), and (21d)), are very simplistic. They need not be, however. Any variables and functional relationships employed by other intertemporal models can also be introduced to the dynamic model. The key difference is that the dynamic model will determine changes in investment on the basis of the current levels of other variables rather than on their equilibrium levels. The dynamic model also projects" capital consumption, capital formation, capital stocks and sectoral capacity.

The approach allows the analyst to make intertemporal comparisons of variables, to discount future values and, therefore, to sum impacts over time. In contrast, the long run impact generated by the static model is an undiscounted total, and as such may be misleading for intertemporal comparisons of benefits and costs.

Finally, the explicit time dimension in the dynamic approach allows the introduction of economic stimulae with important temporal elements such as seasonal or cyclical fluctuations, phased expenditures and one-time investments plus yearly expenditures. The static model is hopelessly unsuited for these situations.

The dynamic model should outperform the static model at estimating the long-run as well. The long-run equilibrium predicted by the dynamic model, while identical to the static equilibrium, should be more precise since it endogenously determines the accelerator effect of changed investment levels. The static long-run equilibrium will be equivalent only if the same investment levels are determined exogenously.
Of course, this greater power of analysis comes at a cost. The data needs have already been alluded to. The estimation of capitaloutput coefficients, lag coefficients and other necessary data are large if the static coefficients have already been estimated. However, they add little extra cost if incorporated into the primary data surveys.

\section{Possible Extensions}

What is the future of dynamic input-output? As so often is the case in methods of this type, data availability and accuracy are important keys to the model's future usefulness. Before the method can be thoroughly evaluated, considerable effort is needed to collect the necessary data. If accurate data cannot be collected at a reasonable cost, the method is of little use.

There are, of course, a nearly infinite number of other possible improvements to the dynamic model. Of interest here are those which are faciliated or encouraged by the dynamic framework. The most obvious extension to this model would be to introduce a spatial dimension. As a minimum, space could be introduced through a framework similar to the static interregional input-output model. A more intriguing possibility is that space could be introduced on a continuous basis, perhaps as hinted at by Isard (1979). If incorporated in this manner space and time would become inseparable determinants of economic levels and rates.

Because of the intimate relationship between space and time, it is likely that the dynamics of a system can only be portrayed accurately in a spatial context. To the extent that the impacts of a shock emanate spatially and temporally from the point of the shock, much like ripples from a stone tossed in a placid pond, the timing of impacts can only be determined if the location is also known.

Perhaps not unrelated to the space-time possibility above is the potential for introducing structural change-particularly endogenous structural change. As a minimum, Miernyk's best practice establishment technique (Miernyk, et al, 1970, pp. 117-125; and Miernyk and Sears, 1974, pp. 21-27) or Almon's approach (1963a, 1963b, 1966) should be possible. Hopefully, technological change can be related to investment levels and, perhaps, expenditure 
levels to relative price changes. Given a sufficient space-time framework, structural change through location decisions of firms could be incorporated.

\section{Conclusions}

This paper describes a variation of the Leontief dynamic input-output framework which was designed for regional economic analysis. The paper argues that the popularity of inputoutput for regional analysis is due to the applicability of the method to the regional situation. It further argues that the dynamic approach broadens and improves upon the static model.

Analysts planning a primary input-output data survey are encouraged to consider collecting the additional data needed to employ the dynamic model.

\section{REFERENCES}

Allen, R. G. D. Macro-Economic Theory: A Mathematical Treatment. London: MacMillan and Company, 1967.

Almon, Clopper. "Consistent Forecasting in a Dynamic Multi-Sector Model." Review of Economics and Statistics XLV, May 1963a, pp. 148-162.

Almon, Clopper. "Numerical Solution of a Modified Leontief Dynamic System for Consistent Forecasting or Indicative Planning." Econometrica 31(October 1963b): 665-678.

Almon, Clopper. The American Economy to 1975. New York: Harper and Row, 1965.

Almon, Clopper, Jr., Margaret B. Buckler, Lawrence M. Horwitz, and Thomas C. Reimbold. 1985: Interindustry Forecasts of the American Economy. Lexington, Massachusetts: D.C. Heath and Company, 1974.

Bargur, Jona. "A Dynamic Interregional Input-Output Model of the California and Western States Water Economy," California University Water Resources Center, Contribution No. 128. University of California at Berkeley, 1969.

Bodkin, Ronald G. "A Large-Scale Input-Output Econometric Model of the Canadian Economy (Candide)," in Advances in Input-Output Analysis: Proceedings of the Sixth International Conference on InputOutput Techniques, Vienria, 1974. Edited by Karen R. Polenske and Jim V. Skolka, Cambridge Publishing Company, Ballinger, 1976.

Bourque, P. J., Richard Conway, Jr., and C. T. Howard. The Washington Projection and Simulation Model. Input-Output Series, University of Washington Graduate School of Business Administration, September 1977.

Emerson, M. Jarvin, Charles F. Lamphear, and Leonard D. Atencio. "Toward a Dynamic Regional Export Model." Annals of Regional Science, 3, No. 2 (December 1969): 127-138.

Fromm, Gary and Lawrence R. Klein, eds. The Brookings Model: Perspective and Recent Developments, NorthHolland, Amsterdam, 1975.

Giarratani, Frank, James D. Maddy, and Charles F. Socher. Regional and Interregional Input-Output
Analysis: An Annotated Bibliography. Morgantown, West Virgina: West Virginia University Library, 1976.

Gossling, W. F. "A Dynamic Model of Capital Replacement," in Capital Coefficients and Dynamic InputOutput Models, pp. 136-152. Edited by W. F. Gossling. London: Input-Output Publishing Company, 1975.

Green, M. J. "Investment Matrices for the United Kingdom: Their Structure and Use in Forecasting," in Capital Coefficients and Dynamic Input-Output Models, pp. 14-35. Edited by W. F. Gossling. London: InputOutput Publishing Company, 1975.

Isard, Walter. "Notes on the Origins, Development and Future of Regional Science." Regional Science Association Papers XLIII, 1979, pp. 9-22.

Johnson, Thomas G. "A Dynamic Input-Output Model for Regional Impact Analysis." Unpublished Ph.D. dissertation, Oregon State University, 1979.

Johnson, Thomas G. Impact of Irrigation Agriculture on the Aggregate Economy of Saskatchewan. Report to Outlook Irrigation Branch, Saskatchewan Department of Agriculture, May 1980, 50 pages.

Johnson, Thomas G. "Solving Dynamic Input-Output Models by Numerical Methods." Simulation 41, No. 3 (September 1983):93-101.

Kendrick, David. "On the Leontief Dynamic Inverse." Quarterly Journal of Economics LXXXVI (November 1972):693-696.

Leontief, Wassily. "Quantitative Input and Output Relations in the Economic System of the United States." Review of Economics and Statistics, 19(1936): 105-125.

Leontief, Wassily. The Structure of the American Economy, 1919-1929, Cambridge, Massachusetts: Harvard University Press, 1941.

Leontief, Wassily. "Dynamic Analysis." Studies in the Structure of the American Economy: Theoretical and Empirical Explorations in Input-Output Analysis. Edited by Wassily Leontief, Hollis B. Chenery, Paul G. Clark, James S. Duesenberry, Allen R. Ferguson, Anne P. Grosse, Robert N. Grosse, Mathilda Holzman, Walter Isard, and Helen Kistin. Oxford University Press, New York, 1953.

Leontief, Wassily. "The Dynamic Inverse," in Contributions to Input-Output Analysis: Proceedings of the Fourth International Conference on Input-Output Techniques, Geneva, January 1968. Vol. 1, pp. 17-46. Edited by Anne P. Carter and Andrew Brody. Amstendam: NorthHolland, 1970.

Liew, Chong K. "Dynamic Multipliers for a Regional Input-Output Model." The Annals of Regional Science, Vol. L.XI (November 1977), No. 3, pp. 94-106.

McLewin, W. "A Traverse Model for Change of Steady Growth Rate," in Capital Coefficients and Dynamic Input-Output Models," pp. 16-36. Edited by W. F. Gossling. London: Input-Output Publishing Company, 1975.

Miernyk, William H. "The West Virginia Dynamic Model and its Implications." Growth and Change, April 1970, pp. 27-32.

Miernyk, W. H., Kenneth L. Shellhammer, Douglas M. Brown, Ronald L. Coccari, Charles J. Gallagher, and Wesley H. Wineman. Simulating Regional Economic Development: An Interindustry Analysis of the West Virginia Economy. Lexington: D.C. Heath and Co., 1970.

Miernyk, W. H. and J. T. Sears. Air Pollution Abatement and Regional Economic Development: An Input-Output Analysis. Lexington, Massachusetts: D.C. Heath, 1974. Moore, F. T. "Regional Economic Reaction Paths." American Economic Review XLV (May 1955):133-55.

Moore, Frederick T. and James W. Petersen. "Regional Analysis: An Interindustry Model of Utah." The Review of Economics and Statistics. Vol. XXXVII, No. 4 (1955):368-83. 
Preston, R. S. "The Wharton Long Term Model: InputOutput Within the Context of a Macro Forecasting Model." in Econometric Model Performance: Comparative Simulations of the U.S. Economy. Edited by Lawrence R. Klein and Edwin Burmeister, University of Pennsylvania Press, Philadelphia, 1976, pp. 271-287.

Rubida, Kirk W. "The Design of Computer Simulation Experiments With an Econometric Model of a Regional Economy: The State of Colorado." The Annals of Regional Science, XII (July 1978), No. 2, pp. 41-53.

Sargan, J. D. "The Instability of the Leontief Dynamic Model." Econometrica 26, July 1958, pp. 381-392.

Schinnar, Arie P. "The Leontief Dynamic Generalized Inverse." Quarterly Joumal of Economics, XCII
(November 1978):641-52.

Treyz, George I. and David J. Ehrlich. "The Regional Economic Forecasting and Simulation (REFS) Model." Amherst, Massachusetts: Regional Economic Models, Inc., March 10, 1982.

Tsukui, Jinkich and Yasusuke Murakami. Turnpike Optimality in Input-Output Systems. Amsterdam: NorthHolland, 1979.

Tung, Fu-Lai, James A. MacMillan and Charles F. Framingham. "A Dynamic Regional Model for Evaluating Resource Development Programs." American Joumal of Agricultural Economics, 58(August 1976):403-414. 